\title{
A path to renal transplantation in Nepal
}

\author{
Enns $\mathrm{J}^{1}$, Aryal $\mathrm{G}^{2}$ \\ ${ }^{1}$ HLA Laboratory, Alka Hospital Pvt. Ltd., Kathmandu, Nepal \\ ${ }^{2}$ Department of Pathology, KIST Medical College and Teaching Hospital, Lalitpur, Nepal
}

\author{
Keywords: \\ Renal Transplant; \\ South Asia; \\ Nepal; \\ Human Leukocyte Antigen
}

\begin{abstract}
End Stage Renal Disease affects many people in the world. There are three methods of renal replacement therapy available to patients: Continuous ambulatory peritoneal dialysis, haemodialysis and transplantation. Transplantation is the most viable and cost effective form of renal replacement therapy that is available for these patients. There are 3 factors required to help ensure a successful renal transplantation program: A well legislated donor and recipient program, Human Leukocyte Antigen testing (pre and post transplant), as well as a post transplant follow up program.
\end{abstract}

\section{INTRODUCTION}

End Stage Renal Disease (ESRD) is a pathology that affects many people throughout the world. The estimated incidence of ESRD is approximately 232 cases per million people annually. ${ }^{1,2}$ There are 3 methods of renal replacement therapy available to patients: Continuous ambulatory peritoneal dialysis (CAPD), haemodialysis (HD) and transplantation. ${ }^{3}$ Of these, transplantation is the most cost effective. It provides the best outcome for these patients as it is the best treatment for increasing their quality of life and life expectancy. ${ }^{1,4,5}$

\section{A Brief History and Background of Kidney Transplantation}

Kidney transplantation originated in the United States in 1954. The first successful renal transplant was done on identical twins by Dr. John Murray. ${ }^{6,7}$ In developed countries, approximately $75 \%$ of the transplants performed

\author{
Correspondence: \\ Dr. Gopi Aryal, $M D, P h D$ \\ Associate Professor \\ Department of Pathology, KIST Medical College and Teaching Hospital \\ GPO Box: 11142, Kathmandu, Nepal \\ E-mail: gopiaryal@hotmail.com
}

use organs from cadaveric donors while the developing countries transplant about $85-100 \%$ of the kidneys from living donors. ${ }^{8,9}$

A global problem is the short supply of available kidneys to be transplanted. In the United States, legislation was drawn up to legitimize organ donation from cadaveric donors as well as defining the conditions under which living donation could occur. In 1984, the National Organ Transplant Act was enacted which made it illegal to buy or sell organs. Using living related donors (LRD) and living unrelated donors (LURD) as a source of organs has aided in increasing the kidney organ pool, but still falls short of the number of kidneys that are required to treat all the patients with ESRD. ${ }^{4}$

Transplantation practices have evolved differently in the developed and developing countries (Table 1). 2, 3, 5-7, 10-15

For the majority of the population in developing countries, the cost of treating ESRD is expensive and the people are poor. Consequently, the number of people that can afford transplantation is around $10 \%$ in the South Asian countries and has set up an environment whereby the poor can be exploited to sell their kidneys. ${ }^{4,14,15}$ 
Table 1. Diversity of Transplant Evolution

\begin{tabular}{lcccccc}
\hline Country & USA & India & Jordan & Iran & Pakistan & Nepal \\
\hline 1st successful kidney transplant & 1954 & 1971 & 1972 & 1968 & 1979 & 2008 \\
Brain death law & $1968^{*}$ & 1999 & 1986 & 2000 & None & None \\
Majority of Transplant types performed & CAD $^{\dagger}$ & LD $^{\ddagger}$ & LD & LD & LD & LD \\
Cadaveric Transplants done & Yes & Yes & Yes & Yes & No & No \\
\hline
\end{tabular}

*Uniform Anatomical Gift Act; ${ }^{\dagger}$ Cadaveric donations, ${ }^{*}$ Living Donations

There has been implementation of cadaveric organ donation programs in some of the South Asian countries but due to religious/social beliefs, a lack of confidence in the brain death laws, inadequate public education and government support, its use is very limited. ${ }^{16}$

As a result, the use of living donors (LD) as a source for kidneys is prevalent. Due to inadequate or no organ transplantation legislation, the global kidney shortage and the poor economics of the South Asian countries, transplant tourism had become a normal practice. ${ }^{4,14}$ Several studies have shown that these allograft recipients had more acute rejections, infections and graft loss. However, the graft survival was comparable to those that were done legally. ${ }^{4}$, $15,17,18$

Whether the transplants are done legally or illegally, there are other factors that contribute to the substandard outcomes of transplantation. One factor is not having a legislated protocol for LD donations which would educate the public, and provide a responsible system for the care of both the donor and recipient before and after the surgery. Another factor is the lack of a standardized system of HLA testing. Both of these processes are costly and would require government support. ${ }^{19,20}$

Successful LD programs ensure that the donation is voluntary and that the donor's safety is of utmost importance. The donor must be educated on the processes, procedures and risks involved with the donation and must understand that they have the option of withdrawing from the program at any time. A medical and psychological evaluation is done to ensure that the donor has no major risk factors that may lead to renal failure later on in life. Lastly, a final informed consent is taken to ensure that the donor has complete understanding of the entire process. ${ }^{19}$

Recipient testing to determine compatibility with the donor is important. The first procedure to be done is $\mathrm{ABO}$ blood group testing followed by HLA testing to ensure compatibility between the donor and recipient. One HLA test to be done to determine compatibility with the donor is the $\mathrm{T}$ cell complement dependent cytotoxicity (CDC) crossmatch in order to rule out any preformed HLA antibodies to the donor's tissue. The other test that can be done is HLA typing. There are conflicting reports on the importance of HLA typing. There are many studies that have shown that graft survival is increased, especially with 0 mismatched HLA antigens ${ }^{19,21-24}$ and that Class II HLA matching is important. ${ }^{24}$ Another study has shown there is no difference in graft survival between unrelated, haploidentical or a totally mismatched kidney allografts. ${ }^{19}$

In developing countries, due to the high costs and lack of adequate public education, HLA testing is limited to a very small number of laboratories in South Asia. ${ }^{2,15}$ In Iran, $\mathrm{ABO}$ blood group matching is the only compatibility testing that is performed. In Pakistan, most centers do not have the ability or adequate facilities to perform HLA testing, therefore, $\mathrm{ABO}$ blood group matching is the only test performed. ${ }^{15}$ India has some facilities that offer HLA typing, basic CDC crossmatching and antibody screening, but these types of testing are rarely done. ${ }^{2}$ Renal recipients from Bangladesh need to travel outside their country to receive their allograft but follow up is done within the country ${ }^{25} \mathrm{In}$ Nepal, transplantation is performed in the country, but the patients are required to go outside of the country to get HLA testing done., ${ }^{3,7}$

\section{What's happening in Nepal?}

In 2000, legislation was passed to legalize transplantation with LDs who are close relatives to the recipients. ${ }^{3,7}$ Nepal performed its first successful kidney transplant in 2008 at the Tribhuvan University Teaching Hospital. ${ }^{7}$ However, the development of a basic infrastructure like a HLA laboratory and Immunflourescence (IF) staining for renal biopsies are still lacking.

There is a LRD program followed here to aid in the selection of a compatible donor and recipient, but the histocompatibility testing requires travel outside of the country, which adds an extra burden to an already costly procedure. ${ }^{3,7}$

In Alka Hospital Pvt. Ltd., the ability to have HLA testing done is currently being developed. Patients and donors will be able to have their molecular HLA typing for class I and Class II determined as well as being able to have an AntiHuman Globulin Complement Dependent Cytotoxicity (AHG-CDC) crossmatch performed. The AHG-CDC assay is used to help determine if the recipient has preformed antibodies to the potential donor. The HLA typing determines the degree of HLA matching between the donor and the 
recipient. Post transplant monitoring will be available for the clinicians to aid them in creating a treatment plan for the patient in a more timely way than having the testing done outside of the country. The testing available for this will be CDC-AHG crossmatching and antibody screening of the patient's sera using ELISA techniques to determine if the patient has developed donor specific antibody (DSA) to the allograft.

Another important methodology being developed here to aid in post transplant monitoring is IF staining of renal biopsies. The IF staining aids in the detection of C4d (DSA) in peritubular capillaries. ${ }^{26}$

\section{DISCUSSION}

With the development of the technical expertise of HLA testing, kidney transplantation in Nepal will afford a better lifestyle and greater life expectancy for recipients at a decreased cost. ${ }^{4}$

Below is a set of guidelines that can be followed in determining a compatible donor for a recipient. ${ }^{3,19,27}$

\section{A. Preliminary Basic Steps}

1. Potential donor is identified and consulted.

a. Risks and benefits fully disclosed

b. Education of their rights - that there is no coercion and that they can change their mind at anytime

2. Recipient/donor educated on all options available for treatment of ESRD. They can be directed to websites that give updates/information of LD practices. ${ }^{28}$

3. Preliminary assessment

a. ABO blood grouping of donor and recipient proceed only if $\mathrm{ABO}$ compatible

b. Complete assessment of the potential- proceed only if medically suitable

i. Blood pressure (at least 2 measurements)

ii. Body Mass index (BMI)

iii. Full medical check up

iv. Psychosocial analysis

B. Next steps - to be done only if donor is suitable

4. HLA CDC-AHG T cell crossmatch - proceed if negative

5. HLA typing of donor and recipient

6. Recipient work up
a. ECG
b. Radiology - urological observations
c. Laboratory testing

7. Review/assessment with Nephrologists

8. Follow up Testing if necessary

9. Final crossmatch

\section{Surgery}

11. Follow up with donor and recipient

\section{CONCLUSION}

There is still a need to make transplantation more affordable for the general population, establish the ability to do immunosuppressive drug monitoring and expand the kidney organ pool with well legislated procedures to include LURD and cadaveric donors. Nepal is well on its way to becoming one of the more advanced centers of transplantation in Southeast Asia.

\section{REFERENCES}

1. Jha V. Current status of end-stage renal disease care in South Asia. Ethn Dis 2009;19:S1-27-32.

2. Abraham G, Shroff S, Nayak KS et al. Deceased-donor renal transplantation program in India. Kidney Int 2010;77:378-80.

3. Sharma VK. Need for renal transplantation programme in Bir Hospital. Kathmandu Univ Med J (KUMJ) 2005;3:191-3.

4. Jafar TH. Organ trafficking: global solutions for a global problem. Am J Kidney Dis 2009;54:1145-57.

5. Dulal RK, Karki S. Nepalese kidney transplant recipient in a follow up clinic: related and unrelated living donor. J Nepal Med Assoc 2008;47:98-103.

6. Yee J. The Third Epoch: "Kidney Plus" Transplantation. Adv Chronic Kidney Dis 2009;16:221-3.

7. Chalise PR, Shah DS, Sharma UK et al. Renal transplantation in Nepal: the first year's experience. Saudi J Kidney Dis Transpl 2010;21:559-64.

8. Akhtar F. Chronic kidney disease, transplantation practices and transplantation law in Pakistan: opportunity for a global meditation. Artif Organs 2009; 33:570-6.

9. Rizvi SA, Naqvi SA, Hussain $Z$ et al. Emerging challenges in transplantation in developing countries. Transplant Proc 2002;34:3146-9.

10. Al Sayyaru AA. The history of renal transplantation in the Arab world: a view from Saudi Arabia. Am J kifney Dis 2008;51:1033-46.

11. Broumand B. Transplantation activities in Iran. Exp Clin tranplant 2005;3:333-7.

12. Rizvi SA, Naqvi SA, Hashmi A et al. Improving kidney and live donation rates in Asia: living donation. Transplant Proc 2004;36:1894-5.

13. Shroff S, Rao S, Kurian G, Suresh S. Organ donation and transplantation-the Chennai experience in India. transplant Proc 2007;39:714-8.

14. Chugh KS. Five decades of Indian nephrology: a personal journey. Am J Kidney Dis 2009;54:753-63.

15. Rizvi AH, Naqvi AS, Zafar NM, Ahmed E. Regulated compensated donation in Pakistan and Iran. Curr Opin Organ Transplant 2009; $14: 124-8$.

16. Shaheen FA, Souqiyyeh MZ. How to improve organ donation in the MESOT countries. Ann Transplant 2004;9:19-21.

17. Krishnan N, Cockwell P, Devulapally $\mathrm{P}$ et al. Organ trafficking for live donor kidney transplantation in Indoasians resident in the west midlands: high activity and poor outcomes. Transplantation 2010;89:1456-61.

18. Alghamdi SA, Nabi ZG, Alkhafaji DM et al. Transplant tourism outcome: a single center experience. Transplantation 2010;90:184-8. 
19. Davis CL, Delmonico FL. Living-donor kidney transplantation: a review of the current practices for the live donor. J Am Soc Nephrol 2005;16:2098-110.

20. Rodrigue JR, Pavlakis M, Danovitch GM et al. Evaluating living kidney donors: relationship types, psychosocial criteria, and consent processes at US transplant programs. Am J Transplant 2007;7:232632.

21. Chelluri LK, Vasantha A, Ratnakar KS. Impact of ethnicity, donor status and HLA matching on renal allograft survival: A single center study. Saudi J Kidney Dis Transpl 2009;20:995-7.

22. Basu G, Daniel D, Rajagopal A, Neelakantan N, John GT. A model for human leukocyte antigen-matched donor-swap transplantation in India. Transplantation 2008;85:687-92.

23. Trivedi VB, Dave AP, Dave JM, Patel BC. Human leukocyte antigen and its role in transplantation biology. Transplant Proc 2007;39:688-93.
24. Opelz G, Wujciak T, Döhler B, Scherer S, Mytilineos J. HLA compatibility and organ transplant survival. Rev Immnogenenet 1999;1:334-42.

25. Rashid HU, Khanam A, Wahab MA, Iqbal KM. Renal transplantation in Bangladesh: experience with conventional therapy Transplant Proc 2003;35:158.

26. Mizutani K, Gotoh M. C4d binding correlated with strong HLA antibodies involved in graft failures. Transplant Proc 2010;42:40215 .

27. Zhao WY, Zhang L, Han S et al. Evaluation of living related kidney donors in China: policies and practices in a transplant center. Clin Transplant 2010;24:E158-62.

28. Kidney Transplantation (online). 2010 [cited 2011Jan 10]. Available from: http://www.nlm.nih.gov/medlineplus/kidneytransplantation. 